\title{
Research trends and performances of breast reconstruction: a bibliometric analysis
}

\author{
Yunzhu Li ${ }^{1}$, Xiaojun Wang ${ }^{1}$, Jørn Bo Thomsen ${ }^{2}$, Maurice Y. Nahabedian ${ }^{3}$, Naohiro Ishii ${ }^{4}$, Warren M. Rozen ${ }^{5}$, \\ Xiao Long ${ }^{1}$, Yuh-Shan $\mathrm{Ho}^{6}$ \\ ${ }^{1}$ Department of Plastic Surgery, Peking Union Medical College (PUMC) Hospital, PUMC and Chinese Academy of Medical Sciences, Beijing, \\ China; ${ }^{2}$ Department of Plastic Surgery, Odense University Hospital and Department of Clinical Research, University of Southern Denmark, \\ Denmark; ${ }^{3}$ Department of Plastic Surgery, Virginia Commonwealth University, Inova Branch, Falls Church, Virginia, USA; ${ }^{4}$ Department of Plastic \\ and Reconstructive Surgery, International University of Health and Welfare Hospital, Japan; ${ }^{5}$ Department of Plastic and Reconstructive Surgery, \\ Frankston Hospital, Australia; ${ }^{6}$ Trend Research Centre, Asia University, Taichung, Taiwan \\ Contributions: (I) Conception and design: Y Li, X Long, YS Ho; (II) Administrative support: Y Li, X Wang, X Long, YS Ho; (III) Provision of study \\ materials or patients: Y Li, X Wang, JB Thomsen, X Long, YS Ho; (IV) Collection and assembly of data: Y Li, JB Thomsen, MY Nahabedian, N \\ Ishii, WM Rozen; (V) Data analysis and interpretation: Y Li, X Wang, JB Thomsen, X Long, YS Ho; (VI) Manuscript writing: All authors; (VII) \\ Final approval of manuscript: All authors. \\ Correspondence to: Xiao Long. Peking Union Medical College Hospital, No. 1, Shuaifuyuan, Dongcheng District, Beijing, China. Email: \\ pumclongxiao@126.com; Yuh-Shan Ho. Trend Research Centre, Asia University, No. 500, Lioufeng Road, Wufeng, Taichung Country 41354, \\ Taiwan. Email: ysho@asia.edu.tw.
}

Background: The need for postmastectomy breast reconstruction surgery has increased dramatically, and significant progress has been made both in implant and autologous based breast reconstruction in recent decades. In this paper, we performed a bibliometric analysis with the aim of providing an overview of the developments in breast reconstruction research and insight into the research trends.

Methods: We searched the Science Citation Index Expanded database and the Web of Science Core Collection for articles published between 1991 to 2018 in the topic domain, using title, abstract, author keywords, and KeyWords Plus. Four citation indicators TCyear, Cyear, $\mathrm{C}_{0}$ and $\mathrm{CPP}_{\text {year }}$ were employed to help analyse the identified articles.

Results: The number of scientific articles in breast reconstruction in this period steadily increased. It took most articles nearly a decade to hit a plateau in terms of citation counts. Plastic and Reconstructive Surgery, Annals of Plastic Surgery, and Journal of Plastic Reconstructive and Aesthetic Surgery published the largest number of articles on breast reconstruction. Nine of the top ten most prolific publications were based in the USA. The research highlights related to breast reconstruction were implant-based breast reconstruction, deep inferior epigastric perforator (DIEP) flap breast reconstruction, and superficial inferior epigastric artery (SIEA) flap breast reconstruction.

Conclusions: This bibliometric analysis yielded data on citation number, publication outputs, categories, journals, institutions, countries, research highlights and tendencies. It helps to picture the panorama of breast reconstruction research, and guide the future research work.

Keywords: Bibliometric citation analysis; Science Citation Index Expanded; Web of Science Core Collection; $Y$-index

Submitted Apr 22, 2020. Accepted for publication Oct 29, 2020.

doi: 10.21037/atm-20-3476

View this article at: http://dx.doi.org/10.21037/atm-20-3476 


\section{Introduction}

Over recent decades, the incidence of breast cancer has risen dramatically. It is the most common cancer diagnosed among women worldwide, with approximately 2,088,849 new cases and 626,679 deaths per year (1). Consequently, the need for postmastectomy breast reconstruction surgery has also grown (2). Since the first description of breast reconstruction by Vincent Czerny in 1895 (3), significant progress has been made both in implant- and autologousbased breast reconstruction in recent decades, reducing complication rates and donor site morbidity and improving cosmesis step by step (4).

Presently, new articles on breast reconstruction are being published in peer-reviewed journals every day. The problem with the presence of such a substantial amount of evidence is in identifying the most significant or influential articles. Bibliometric citation analysis, a broadly used method to map the literature, can give evidence-based insights into the development of trends in breast reconstruction and reveal better reconstruction strategies for postmasctectomy patients $(5,6)$. Typically, this method analyzes the publication outputs of countries, research institutions, journals, and research domains (7). However, there are many deficiencies in conventional bibliometric analysis. For instance, the change in the publication or citations numbers of countries and institutions, may not be an indication of a trend in a research domain. More information consisting of article title, author keyword, KeyWords Plus, and abstracts should be included in the study of these $(8,9)$.

Aiming to map the trends breast reconstruction research for the period falling between 1991 and 2018, we conducted a quantitative description of publications which included information on Web of Science categories, major countries, institutions, journals, and research trends and tendencies. We hope this analysis will provide researchers with a clearer, more up-to-date understanding of the state of breast reconstruction research and help guide the future work.

\section{Methods}

\section{Identification of related articles}

The data in this study was collected from the Science Citation Index Expanded (SCI-EXPANDED) database of the Clarivate Analytics (formerly known as the Thomson Reuters and the Institute for Scientific Information) Web of Science Core Collection (data last updated on January 06, 2020). The keywords "breast reconstruction", "breasts reconstructed", "breasts reconstruction", "breast reconstructions", and "breast reconstructive" were searched for in the topic domain, using title, abstract, author keywords, and KeyWords Plus, in the Web of Science Core Collection within the publication years between 1991 and 2018. KeyWords Plus supplies additional search terms extracted from the titles of articles cited by authors in their bibliographies and footnotes in the Institute of Science Information (ISI) (now Clarivate Analytics) database, and substantially augments title-word and author-keyword indexing (10). This yielded a total of 8,226 documents from breast reconstruction-related publications.

Those documents only found by KeyWords Plus were more likely to be unrelated to the term "breast reconstruction" (11), and use of the "front page" filter has been proposed to prevent the inclusion of unrelated publications in analysis $(12,13)$. This involves only considering those documents whose "front page", including the title, abstract, and author keywords, contains the chosen keywords. Finally, 6,922 documents ( $84 \%$ of 8,226 documents) were defined as breast reconstruction research publications. The full record of SCI-EXPANDED and the number of citations in each year for each document were checked and downloaded into Microsoft Excel 2016, and additional coding was manually performed. The journal impact factors $\left(\mathrm{IF}_{2018}\right)$ were taken from the fournal Citation Reports (FCR) published in 2018.

\section{Statistical analysis}

In the SCI-EXPANDED database, the corresponding author is designated as the "reprint author", but "corresponding author" was kept as the primary term instead of "reprint author" (14). In cases where there were multiple corresponding author articles, only the last corresponding author, institute, and country was considered. In a single-author article, where authorship is unspecified, the single-author was considered both the first author and the corresponding author (15). Similarly, for an article from a single institution, the institution was both classified as the first author institution and the corresponding author institution (15). Affiliations in England, Scotland, Northern Ireland, and Wales were reclassified those of the United Kingdom (UK) (16). Affiliations in Hong Kong were included as those of China (12).

The 4 following citation indicators were used to characterize the articles (14): the total number of citations from Web of Science Core Collection from publication to the end of the most recent year $\left(\mathrm{TC}_{\mathrm{year}}\right)(17)$; the number 
Table 1 Citations and authors according to publication type

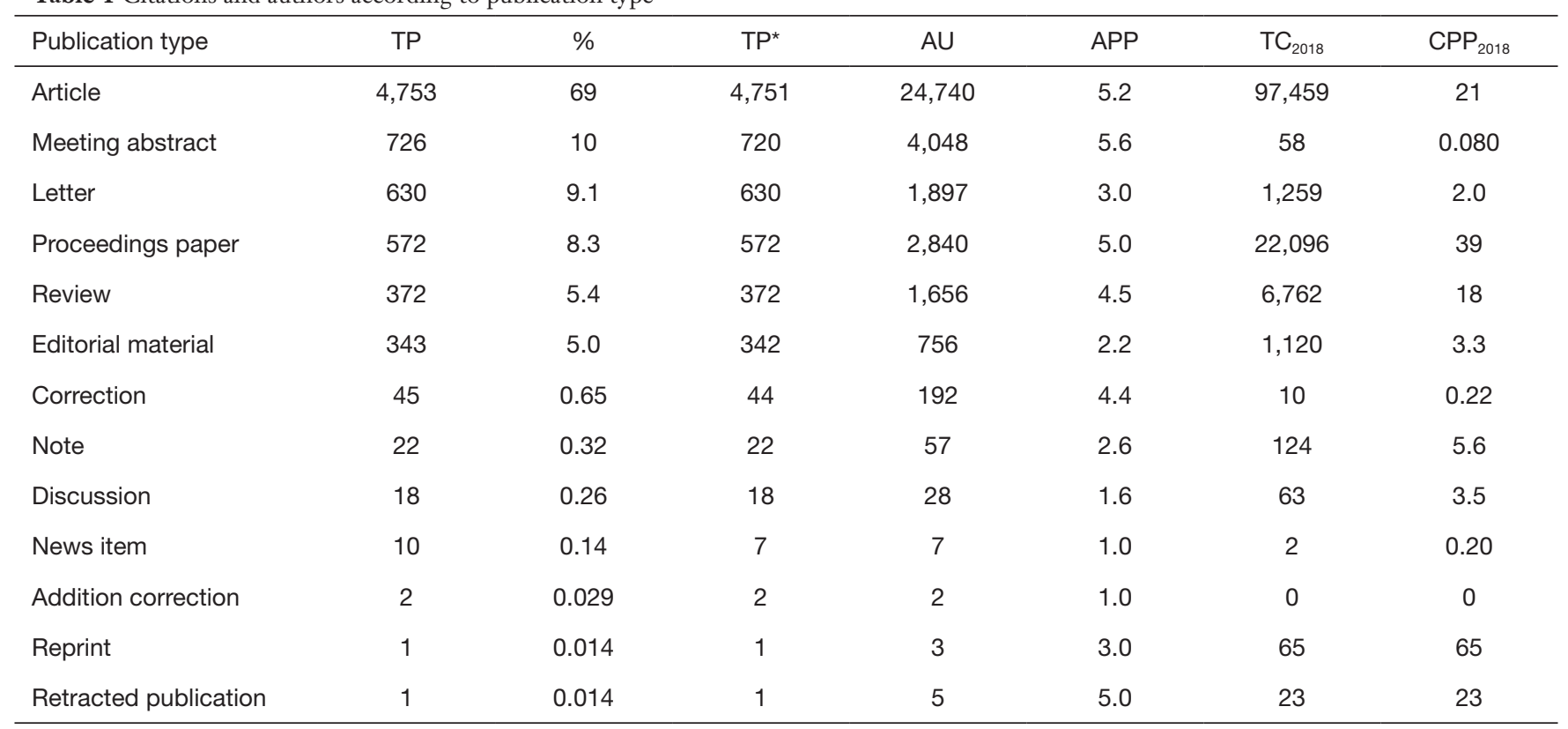

TP, number of publications; TP*, number of publications with author information; AU, number of authors; APP, number of authors per publication; $\mathrm{TC}_{2018}$, the total number of citations from Web of Science Core Collection since publication to the end of 2018; $\mathrm{CPP}_{2018}$, number of citations $\left(\mathrm{TC}_{2018}\right)$ per publication (TP).

of citation of an article in the most recent year only $\left(\mathrm{C}_{\text {year }}\right)(14)$; the number of citations in the publication year $\left(\mathrm{C}_{0}=0\right)(18)$, and the total number of citations per publication $\left(\mathrm{CPP}_{\text {year }}=\mathrm{TC}_{\text {year }} / \mathrm{TP}\right)$.

\section{Results and discussion}

\section{Characteristics of publication types}

The distribution of publication types from the Web of Science is a frequently analyzed issue in medical-related topics $(19,20)$. Recently, the idea of $\mathrm{TC}_{\text {year }}$, defined as the citation count from Web of Science Core Collection from publication to the latest year, was proposed (17). It allows total citations to be a constant and thus enables for its repeated use and monitoring. Citations per publication $\left(\mathrm{CPP}_{\text {year }}=\mathrm{TC}_{\text {year }} / \mathrm{TP}\right)$ can also be used in this way. Recently, the number of authors per publication (APP) was proposed (21). Table 1 shows the characteristics of 13 publication types, including 4,753 articles $(69 \%$ of the 6,922 publications) with an APP of 5.2. A sum of 726 meeting abstracts came from 65 journals, mainly European Fournal of Cancer (91 meeting abstracts; 13\% of 726 meeting abstracts), Annals of Surgical Oncology (81; 11\%), and Cancer Research $(72 ; 10 \%)$. Notably, publications are classified into
2 types in the Web of Science Core Collection; for example, the one entitled "Breast reconstruction with perforator flaps" was classified both as an article and a retracted publication (22); therefore, the sum of percentages was greater than $100 \%$. A notice was published for the retracted article in 2008 explaining that its retraction was due to the dual publication of this article (23). In addition, 572 proceedings papers were also classified as articles.

A document reprint had the highest 2018 citations per publication $\left(\mathrm{CPP}_{2018}=65\right)$ and could be attributed to only 1 reprint titled "Enhancing patient outcomes in aesthetic and reconstructive breast surgery using triple antibiotic breast irrigation: Six-year prospective clinical study" (24) by Adams et al. with a $\mathrm{TC}_{2018}$ of 65 ; it was reprinted from Plastic and Reconstructive Surgery in the same year (24). The paper and following papers examined if rinsing the implant cavity with antibiotics could lower the rate of subsequent capsular contracture. Capsular contracture has long been an issue after implant-based breast reconstruction and augmentation. It not only hampers the aesthetic outcome but also, in some severe cases, requires re-operation thus creates heavy financial burden (25). Current study implies that it is related to an inflammatory response triggered by bacterial contamination $(26,27)$. It is a common practice to 


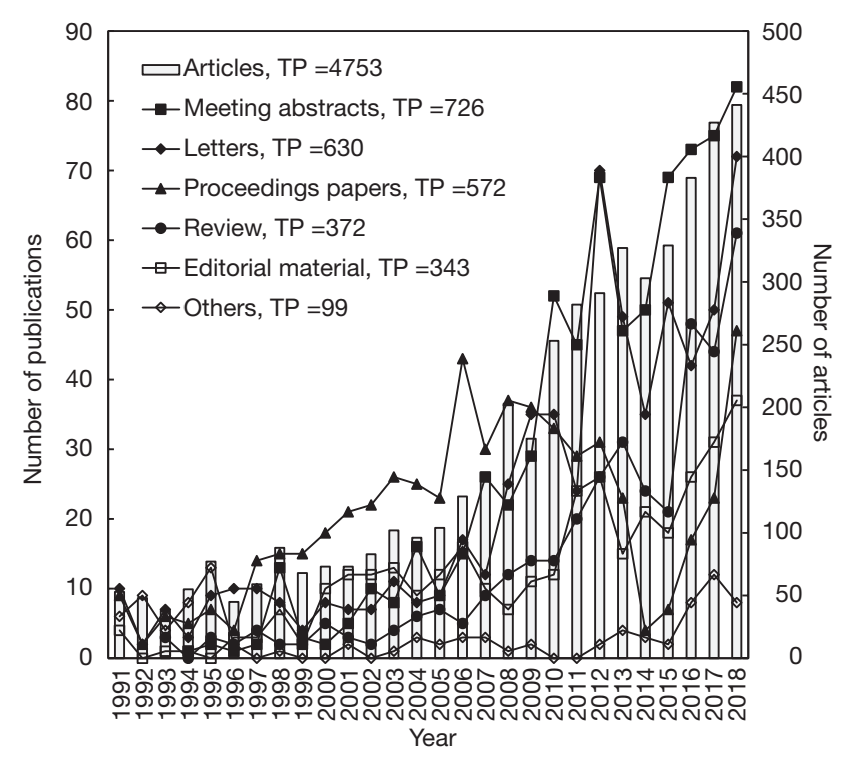

Figure 1 Pattern of the distribution of publication types in the period from 1991 to 2018.

irrigate the implant together with the pocket with antibiotic solutions to decrease the chance of capsular contracture in breast reconstruction and augmentation. However, it was not until 2006 when Adams et al. were able to achieve a lower rate of capsular contracture compared with other known reports that clinical evidence for this practice was provided. Since then, the research on this topic has blossomed (28), but unfortunately, no agreement has been reached as to whether the irrigation is helpful much less viable as a standard antibiotic protocol.

The use of irrigation with antibiotics following implantbased breast reconstruction is a matter of debate. Irrigation probably also limits the overall rate of infections and implant removals following reconstruction. In some centers, no irrigation is used, others use irrigation with 1 antibiotic, and as described above, some use irrigation with triple antibiotics. For the individual patient, the more antibiotics used the better; however from a societal perspective, the use of antibiotic has to be limited to avoid the global development of resistant bacteria, and the cautious use of irrigation with antibiotics is advised.

It was unusual that the $\mathrm{CPP}_{2018}$ of articles $\left(\mathrm{CPP}_{2018}=21\right)$ was higher than that of reviews $\left(\mathrm{CPP}_{2018}=18\right)$. Meeting abstracts items had the highest APP of 5.6 followed by articles (5.2), retracted publications (5.0), and proceedings papers (5.0).

Figure 1 shows that articles, meeting abstracts, and letters rose significantly in the last decade with a similar development trend pattern.

Among all publication types, 4,753 publications were articles and thus were further analyzed, and $95 \%$ of the articles were written in English. Other languages represented were French (135 articles; $2.8 \%$ ), German (64; $1.3 \%)$, Korean (12; $0.25 \%)$, Spanish (10; $0.21 \%)$, Hungarian (5;0.11\%), Serbian (2;0.042\%), Slovenian $(2 ; 0.042 \%)$, and one in each of Icelandic, Italian, and Polish. Articles published in English had, as would be expected, a higher $\mathrm{CPP}_{2018}$ of 21 which was higher than that for articles published in non-English with a $\mathrm{CPP}_{2018}$ of 3.1. The most frequently cited non-English article was "BEAULI ${ }^{\mathrm{TM}}$ : eine neue Methode zur einfachen und zuverlässigen Fettzell-Transplantation" with the English title "BEAULI" : A new and easy method for largevolume fat grafts" (29), which was published in German in Handchirurgie Mikrochirurgie Plastische Chirurgie, and had a $\mathrm{TC}_{2018}$ of 43 . The authors invented a new fat-harvesting method called the BEAULI ${ }^{\mathrm{TM}}$ method, by which the fat was is in very small particles by water-assisted liposuction and is then reinjected after separation from excessive water by the Lipocollector ${ }^{\circledR}$. They accomplished a permanent take rate of $76 \% \pm 11 \%$ of the grafted fat at 6 months follow-up in 35 aesthetic patients.

Fat grafting can be used for total breast reconstruction, both immediate and delayed, in selected women with an adequate body mass index BMI; however, it often has to be combined with a flap, not only for increased volume, but also to act as an additional matrix for the fat $(30,31)$. Typically, the indication for breast reconstruction using fat grafting is when the patient wants breast reconstruction using limited surgery and when comorbidities do not allow for longer surgical procedures. The patient should have a relative high BMI, thick and preferably non-radiated skin flaps following mastectomy.

\section{Characteristics of citations}

In order to understand characteristics of citations, the relations between CPP and article life were studied. The CPP of breast reconstruction articles sharply increased to a peak of 3.03 in the fourth year after publication and decreased afterwards (Figure 2).

\section{Characteristics of publication outputs}

A total of 4,753 breast reconstruction articles in SCI- 


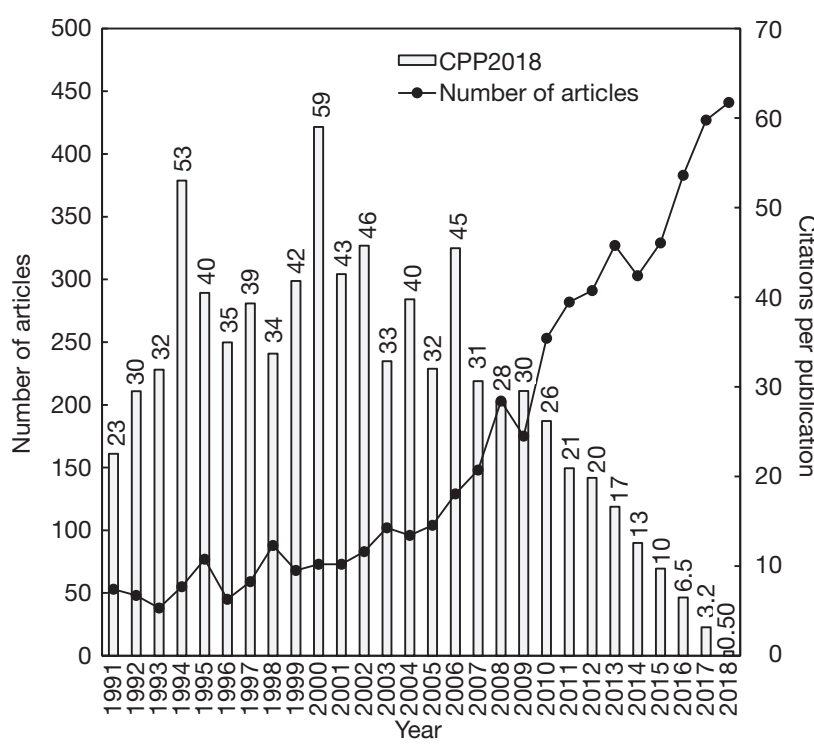

Figure 2 Number of breast reconstruction articles and citations per publication by year.

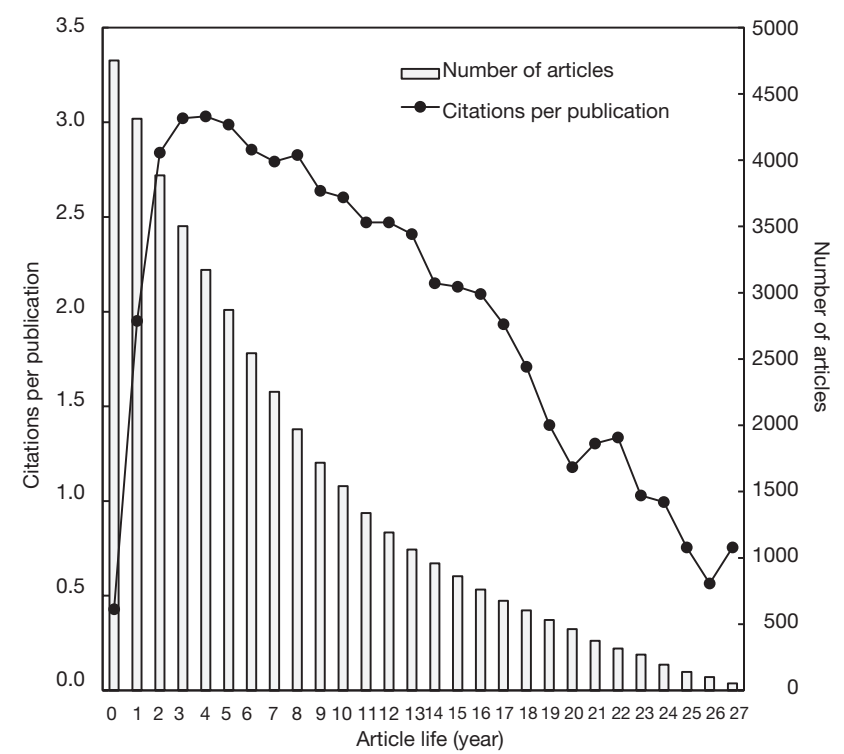

Figure 3 Citations per publication by article life.

EXPANDED were found. Using the relation of the total number of articles (TP) in a year with their citations per publication $\left(\mathrm{CPP}_{\text {year }}=\mathrm{TC}_{\text {year }} / \mathrm{TP}\right)$ by year was proposed to comprehend the impact changes of an article in a research domain (14). Figure 3 presents the distribution of the annual number of breast reconstruction articles (TP) and their $\mathrm{CPP}_{2018}$ by year, which is expressed as $\mathrm{TC}_{2018} / \mathrm{TP}$. The number of articles increased from 1991 to 2005, with slight fluctuations. The scientific research output in this period of time has further stimulated the following research.

Time is always needed to accumulate citations for an article. The number of articles in breast reconstruction reached 441 in 2018. As seen in Figure 3, it took the number of breast reconstruction articles nearly a decade to reach a peak and then decline. It has been recommended that to assess the impact of a paper, the total citations within a minimum of 1 decade is required (13). For instance, a total of 3,651 breast reconstruction articles $(77 \%$ of 4,753 articles) had no citations in the publication year $\left(\mathrm{C}_{0}=0\right)$. In addition, only $13 \%$ and $28 \%$ of the top $100 \mathrm{C}_{0}$ articles were still in the top $100 \mathrm{TC}_{2018}$ and $\mathrm{C}_{2018}$ articles respectively. The years 2000 and 1994, with 73 and 55 articles respectively, had higher citations per publication with a $\mathrm{CPP}_{2018}$ of 59 and 53 respectively, compared to the other years of the 1991-2018 period.

\section{Web of Science categories and journals}

Fournal Citation Reports ( $\mathcal{F C R}$ ) indexed 9,258 journals with citation references in $178 \mathrm{Web}$ of Science categories in SCIEXPANDED in 2018. The breast reconstruction related articles were published in 425 journals in $77 \mathrm{Web}$ of Science categories in SCI-EXPANDED.

The Web of Science category of surgery dominated in breast reconstruction studies with 3,691 articles (78\% of 4,750 articles had the information of their categories in Web of Science), followed by oncology (817 articles; $17 \%)$, obstetrics and gynecology (306; 6.4\%), radiology, nuclear medicine and medical imaging $(115 ; 2.4 \%)$, general and internal medicine $(111,2.3 \%)$, orthopedics (70; $1.5 \%)$, biomedical engineering $(41 ; 0.86 \%)$, research and experimental medicine (39;0.82\%), multidisciplinary sciences $(38 ; 0.80 \%)$, and health care sciences and services (32; $0.67 \%)$. Journals could be classified in more than 1 category in Web of Science; for example, Breast was listed in both "oncology" and "obstetrics and gynecology", and thus the total percentage was greater than $100 \%$.

In total, 4,753 breast reconstruction articles were published in 425 journals, 44 of which were not listed in SCI-EXPANDED in 2018. Table 2 shows the top 10 productive journals, where $61 \%$ of all articles were published. Plastic and Reconstructive Surgery in Web of Science category of surgery published the largest number of articles (21\% of 4,753 articles) with an $\mathrm{IF}_{2018}$ of 3.95 , followed by Annals of Plastic Surgery and Fournal of Plastic 
Table 2 The top 10 most prolific journals

\begin{tabular}{lccc}
\hline Journal & $\mathrm{TP}(\%)$ & $\mathrm{IF}_{2018}$ & Web of Science category $^{\mathrm{CPP}_{2018}}$ \\
\hline Plastic and Reconstructive Surgery & $987(21.0)$ & 3.946 & Surgery \\
Annals of Plastic Surgery & $658(14)$ & 1.448 & Surgery \\
Journal of Plastic Reconstructive and & $381(8.0$ & 2.228 & Surgery \\
Aesthetic Surgery & $167(3.5)$ & 1.399 & Surgery \\
Aesthetic Plastic Surgery & $133(2.8)$ & 1.945 & Surgery \\
Microsurgery & $129(2.7)$ & 3.494 & Oncology, obstetrics and \\
Breast & $124(2.6)$ & gynecology & Surgery \\
Journal of Reconstructive Microsurgery & $113(2.4)$ & 1.837 & Surgery \\
Annales de Chirurgie Plastique Esthetique & $103(2.2)$ & 0.714 & 10 \\
Annals of Surgical Oncology & $96(2.0)$ & 3.681 & Oncology, surgery \\
Clinics in Plastic Surgery & 1.215 & Surgery \\
\hline
\end{tabular}

TP, number of articles; \%, the percentage of articles in total publications; $\mathrm{IF}_{2018}$, journal impact factor in 2018 ; $\mathrm{CPP}_{2018}$, number of citations $\left(\mathrm{TC}_{2018}\right)$ per publication (TP).

Reconstructive and Aesthetic Surgery. Breast reconstructionrelated articles in Plastic and Reconstructive Surgery also had the highest $\mathrm{CPP}_{2018}$ of 39, while articles in Annales de Chirurgie Plastique Esthétique with a lower $\mathrm{IF}_{2018}(0.714)$ had a lower $\mathrm{CPP}_{2018}$ of 3.8 .

The journal with the highest $\mathrm{IF}_{2108}$ in 425 journals was $C A$ : A Cancer Fournal for Clinicians $\left(I F_{2108}=223.679\right)$ with 1 article entitled "Breast reconstruction following mastectomy" by Bostwick (32). The journal ranked not only top in the Web of Science category of oncology with 229 journals but also ranked the top in SCI-EXPANDED with 9,258 journals. The article was written by John Boswick, a giant in plastic surgery. He is known worldwide for his enormous contributions to the specialty, especially in post-mastectomy breast reconstruction, and was one of the first to propose the application of rectus abdominis myocutaneous flap to reconstruct the post-mastectomy breast (33). His book, his hundreds of articles, and his teaching at Emory University have helped to cultivate countless of young plastic surgeons. In recognition of his dedication, he was honored with the James Barrett Brown award in 1979 and the Pickerell award in 2001 (34,35).

Other journals with high $\mathrm{IF}_{2108}$ include the New England Fournal of Medicine $\left(\mathrm{IF}_{2108}=70.670\right)$, the top journal in Web of Science category of general and internal medicine, which had 2 breast reconstruction articles, Lancet Oncology $\left(\mathrm{IF}_{2108}\right.$ $=35.386$ ) with 3 articles, Nature Reviews Clinical Oncology
$\left(\mathrm{IF}_{2108}=34.106\right)$ with 1 article; Fournal of Clinical Oncology

$\left(\mathrm{IF}_{2108}=28.349\right)$ with 7 articles; and $\mathcal{F A M A}$ Oncology $\left(\mathrm{IF}_{2108}\right.$ $=22.416$ ) with 2 articles.

\section{Publication performances: countries/regions and institutions}

In total, 18 articles ( $0.38 \%$ of 4,753 articles) had no author affiliation information in SCI-EXPANDED, while the other 4,735 articles had author affiliations from across 73 countries/regions. Among them, 4,256 articles (90\% of 4,735 articles) originated from a single country, with authors from 59 different countries, while $479(10 \%)$ articles were global collaborations and included authors from 66 different countries. Table 3 lists the 12 most prolific countries (TP $>100$ ) using 6 publication indicators: total number of articles (TP), single-country articles (SP), internationally collaborated articles (CP), first-author articles (FP), corresponding-author articles (RP), and single-author articles (SP). The G7 countries (The USA, the UK, Japan, Italy, Germany, France, and Canada) published 3,511 articles ( $74 \%$ of 4,735 articles) with a $\mathrm{TC}_{2018}$ of 79,251 (81\% of 97,311 citations). Overall, the USA took the leading position in the 6 publication indicators with a TP of 2,153 articles ( $45 \%$ of 4,735 articles), an IP of 1,942 articles (46\% of 4,256 country independent articles), a CP of 211 articles ( $44 \%$ of 479 internationally collaborative articles), an FP of 
Table 3 Top 12 most prolific countries with 6 publication indicators

\begin{tabular}{|c|c|c|c|c|c|c|c|}
\hline Country & TP & TP R (\%) & IP R (\%) & CP R (\%) & FP R (\%) & RP R (\%) & SP R (\%) \\
\hline UK & 458 & $2(9.7)$ & $2(7.6)$ & $2(28)$ & $2(8.0)$ & $2(8.0)$ & $2(4.8)$ \\
\hline Italy & 284 & $3(6.0)$ & $4(4.8)$ & $4(16)$ & $3(5.2)$ & $3(5.2)$ & $22(0.43)$ \\
\hline France & 267 & $4(5.6)$ & $3(5.3)$ & $8(8.4)$ & $4(5.1)$ & $4(5.1)$ & $3(3.5)$ \\
\hline Germany & 192 & $6(4.1)$ & $5(3.4)$ & $6(10)$ & $5(3.5)$ & $5(3.6)$ & $3(3.5)$ \\
\hline Australia & 152 & 7 (3.2) & $9(2.4)$ & $5(10)$ & $8(2.8)$ & $8(2.9)$ & $5(2.6)$ \\
\hline South Korea & 140 & $8(3.0)$ & $6(3.1)$ & 27 (1.3) & $7(2.9)$ & $7(2.9)$ & $9(1.7)$ \\
\hline Japan & 138 & $9(2.9)$ & $7(3.0)$ & $21(2.3)$ & $9(2.8)$ & $9(2.8)$ & 7 (2.2) \\
\hline China & 107 & $12(2.3)$ & $13(1.9)$ & $12(5.4)$ & $12(2.0)$ & $12(2.0)$ & $\mathrm{N} / \mathrm{A}$ \\
\hline
\end{tabular}

TP, number of total articles; IP, independent articles; CP, collaborative articles; FP, first-author articles; RP, corresponding-author articles; SP, single-author articles; R, rank; N/A, not available.

2,044 articles (43\% of 4,735 first-author articles), an RP of 2,009 articles ( $43 \%$ of 4,666 corresponding author articles), and an SP of 135 articles (58\% of 231 single-author articles). China was the only country that published more than 100 articles without single-author articles.

Regarding institutions, 2,078 articles (44\% of 4,735 articles) were single-institution studies only, whereas 2,657 articles $(56 \%)$ were dual-institution or multiple-institution articles. Table 4 summarizes the characteristics of the top 10 most prolific institutions with 100 or more articles: 9 of the top 10 were based in the USA, with The University of Toronto in Canada being the only institution outside the USA that placed. The Memorial Sloan Kettering Cancer Center in the USA took the leading position in 4 publication indicators with a TP of 144 articles $(3.0 \%$ of 4,735 articles), a CP of 95 articles (3.6\% of 2,657 interinstitutionally collaborated articles), an FP of 84 articles ( $1.8 \%$ of 4,735 first-author articles), and an RP of 85 articles ( $1.8 \%$ of 4,666 corresponding-author articles). The University of Texas in USA had the largest number of independent institution articles, with an IP of 57 articles (2.7\% of 2,078 institutional independent articles), and single-author articles, with an SP of 11 articles (4.8\% of 231 single author articles). Neither the University of Michigan nor Northwestern University in USA had single-author articles.

\section{Publication performances: authors}

A total of 4,751 articles had author information. The mean number of authors per article was 5.2. The maximum number was 25 . The main authorship ranged from 2 to 6 authors in an article, with 768 articles (16\% of 451 articles) being written by 4 authors, 764 (16\%) being written by 5 authors, 620 (13\%) being written by 6 authors, 600 (13\%) being written by 3 authors, and 493 (10\%) being written by 2 authors.

First and corresponding authors has the most contributions to the overall paper (36,37). To evaluate the publication potential and scientific contributions of authors, institutions, and countries in relation to the numbers of first-author articles (FP) and corresponding-author articles (RP), the Y-index was proposed (14). The Y-index has two parameters $(\mathrm{j}, \mathrm{h})$ and is expressed as follows:

$$
\begin{aligned}
& j=F P+R P \\
& h=\tan ^{-1}\left(\frac{R P}{F P}\right)
\end{aligned}
$$

As shown in Figure 4, the author with the equal number of first-author articles and corresponding-author articles 
Table 4 Top 10 productive institutions with six publication indicators

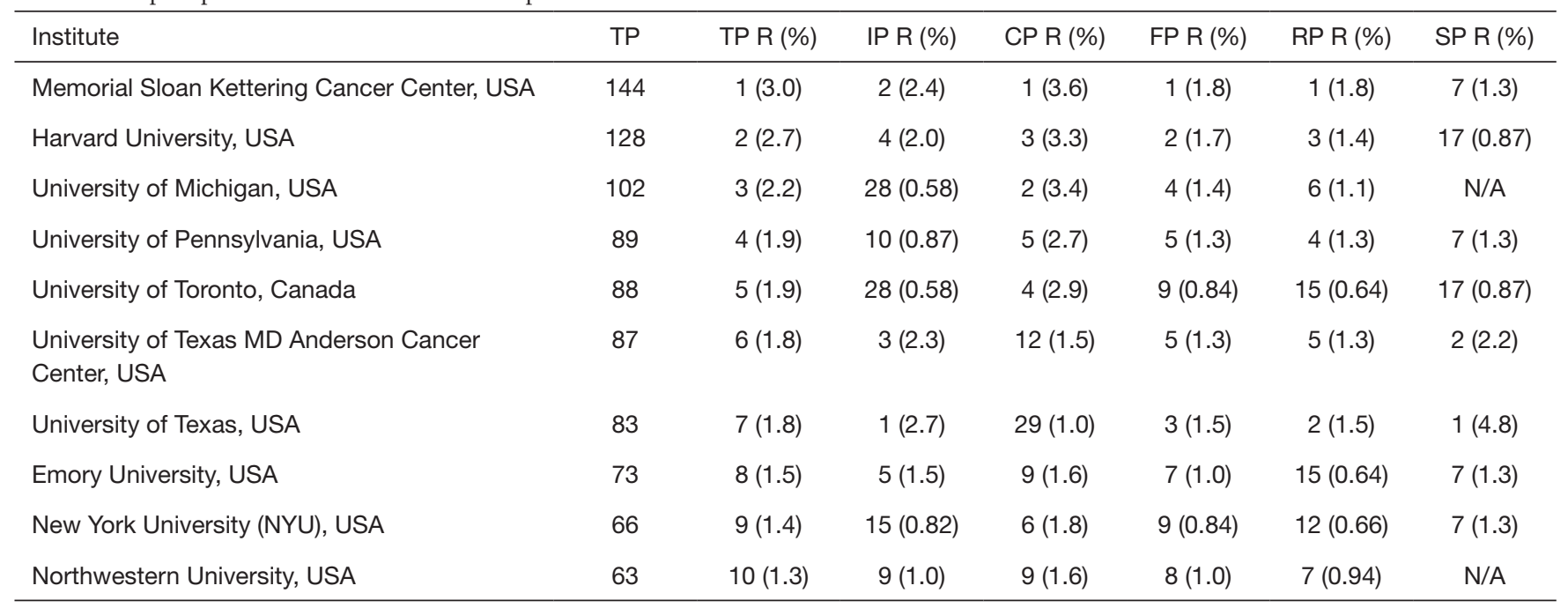

TP, total number of highly cited articles; TPR (\%), IPR (\%), CPR (\%), FPR (\%), RPR (\%), and SPR (\%), the rank and percentage of total articles, single-institution articles, inter-institutionally collaborated articles, first-author articles, corresponding-author articles, single-author articles in their total articles; N/A, not available.

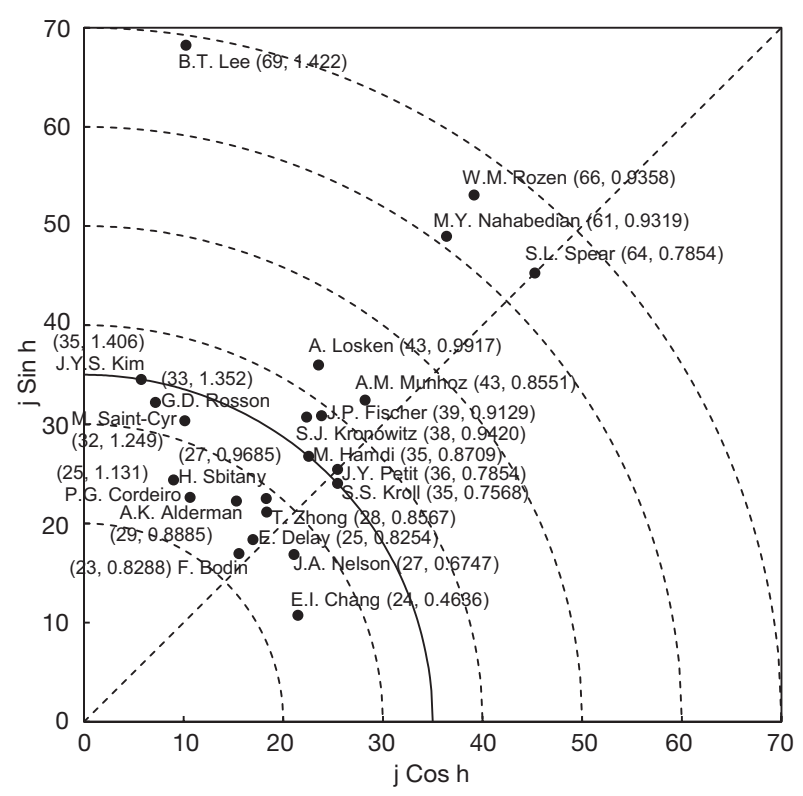

Figure 4 Top 23 authors with Y-index $(j \geq 23)$.

would be placed on the diagonal line with an $b$ value of 0.7854 (in radian). The higher number of correspondingauthor articles an author had, the higher value that $b$ would be given, with these values corresponding to an upper-left placement of an author (Figure 4). Conversely, the higher number of first-author articles an author had, the lower value that $h$ would be given, with these values corresponding to a lower-right placement of the author (Figure 4).

A total of 4604 breast reconstruction articles $(97 \%$ of 4,753 articles) with first authors and corresponding authors in SCI-EXPANDED were analyzed by $Y$-index. The 4,604 breast reconstruction articles were contributed by 12,611 authors. Only 1,888 authors (15\% of the 12,611 authors) had both a first- and corresponding-author article. In particular, the number of authors with only corresponding-author articles $(b=\pi / 2)$ was $672(5.3 \%$ of the 12,611 authors), the number of authors with more corresponding-author articles than first-author articles $(\pi / 2>b>0.7854)$ was $228(1.8 \%)$, the number of authors with equivalent numbers of firstauthor and corresponding-author articles $(b=0.7854)$ was $1,502(12 \%)$, the number of authors with more first-author articles than corresponding-author articles $(0.7854>b>0)$ was $158(1.3 \%)$, the number of authors with only firstauthor articles $(b=0)$ was $1,126(8.9 \%)$. Figure 4 illustrates the top 23 potential authors with $j \geq 24$. B.T. Lee $(69,1.422)$ published 85 breast reconstruction articles including 9 firstauthor articles and 60 corresponding-author articles. Lee had the maximum $j$ value of 66 , followed by W.M. Rozen (66, 0.9358), S.L. Spear (64, 0.7854), and M.Y. Nahabedian (61, 0.9319). Among these 23 authors, only S.S. Kroll (35, 0.7568), J.A. Nelson (27, 0.6747), and E.I. Chang (24, 0.4636 ) published a larger number of first-author articles than corresponding author articles. S.L. Spear $(64,0.7854)$ and J.Y. Petit $(36,0.7854)$ positioned along the diagonal line ( $b=0.7854)$ had an equivalent number of first-author and 
Table 5 The top 10 most frequently cited articles in breast reconstruction

\begin{tabular}{|c|c|c|c|c|}
\hline Rank $\left[\mathrm{TC}_{2018}\right]$ & Rank $\left[\mathrm{C}_{2018}\right]$ & Rank $\left[\mathrm{C}_{0}\right]$ & Title & Reference \\
\hline $2[403]$ & $72[15]$ & $404[1]$ & $\begin{array}{l}\text { The donor site morbidity of free DIEP flaps and free TRAM flaps for } \\
\text { breast reconstruction }\end{array}$ & Blondeel et al. [1997] \\
\hline 3 [383] & 1503 [2] & $14[9]$ & $\begin{array}{l}\text { Risk of connective-tissue diseases and other disorders after breast } \\
\text { implantation }\end{array}$ & Gabriel et al. [1994] \\
\hline 5 [342] & $86[14]$ & $1,103[0]$ & $\begin{array}{l}\text { Role of breast reconstructive surgery in physical and emotional } \\
\text { outcomes among breast cancer survivors }\end{array}$ & Rowland et al. [2000] \\
\hline 6 [335] & $8[32]$ & $1,103[0]$ & $\begin{array}{l}\text { Complications in postmastectomy breast reconstruction: Two-year } \\
\text { results of the Michigan breast reconstruction outcome study }\end{array}$ & Alderman et al. [2002] \\
\hline 8 [320] & $1[71]$ & $5[15]$ & A paradigm shift in U.S. breast reconstruction: Increasing implant rates & Albornoz et al. [2013] \\
\hline 9 [313] & $5[37]$ & $1,103[0]$ & $\begin{array}{l}\text { Comparison of psychological aspects and patient satisfaction following } \\
\text { breast-conserving surgery, simple mastectomy and breast reconstruction }\end{array}$ & Al-Ghazal et al. [2000] \\
\hline $10[284]$ & $72[15]$ & $1,103[0]$ & Skin-sparing mastectomy: Oncologic and reconstructive considerations & Carlson et al. [1997] \\
\hline
\end{tabular}

$\mathrm{TC}_{2018}$, the total number of citations from Web of Science Core Collection since publication to the end of 2018; $\mathrm{C}_{2018}$, the number of citation of an article in 2018 only; C0, the number of citations in the publication year.

corresponding-author articles. Eighteen authors published more corresponding-author articles than first-author articles $(b>0.7854)$. $Y$-index $(j, b)$ can help discern the significance of the authors especially when $j(F P+R P)$ value is the same (38). For instance, the $j$ value of J.Y.S. Kim (35, 1.406), M. Hamdi (35, 0.8709), and S.S. Kroll (35, 0.7568) were identical $(j=35)$, but their $b$ value $(1.406,0.8709$, and 0.7568 respectively) were different. The same $j$ value indicated that they had the same publication potential but variant scientific contributions. J.Y.S. Kim had the greatest contribution as the corresponding author followed by M. Hamdi and S.S. Kroll. Nevertheless, these data have bias potential, as it cannot distinguish between different authors with an identical name, or identify the same author with different names over time (39).

\section{The most frequently cited articles and the highest impact articles in 2018}

Highly cited publications do not always enjoy high publicity immediately after publication (18). The citation counts received in latest year of $2018\left(\mathrm{C}_{2018}\right)$ and in the publication year $\left(\mathrm{C}_{0}\right)$ might help to better recognize the impact development of a highly cited article (14). In breast reconstruction studies, the rankings of 4753 articles based on $\mathrm{TC}_{2018}, \mathrm{C}_{2018}$ or $\mathrm{C}_{0}$ were different. A total of 1,608 articles (34\% of 4,753 articles) received no citation in the latest year $\left(\mathrm{C}_{2018}=0\right)$ while $3,651(77 \%)$ articles received no citation in the initial year right after publication $\left(\mathrm{C}_{0}=0\right)$. Furthermore, only $13 \%$ and $28 \%$ of the top $100 \mathrm{C}_{0}$ articles were also in the top $100 \mathrm{TC}_{2018}$ and $\mathrm{C}_{2018}$ articles respectively. In recent years, high impact articles in the latest year in a Web of Science category of research topic were evaluated by using a citation indicator, $\mathrm{C}_{\text {year }}(12,14)$. The citation history of high impact articles in 2018 was further proposed.

Table 5 demonstrates the top 10 most frequently cited articles. The citation life of the top 10 most frequently cited articles is presented in Figure 5. The most frequently cited breast reconstruction article was published by Allen and Treece in 1994 (40). Its annual number of citations increased rapidly right after its publication and reached a plateau in 2003. The muscle-sparing deep inferior epigastric perforator (DIEP) flap described in this article enabled a satisfying breast reconstruction outcome with minimal abdominal wall morbidity. Although it enjoyed a significant increase in application, a further development was limited 


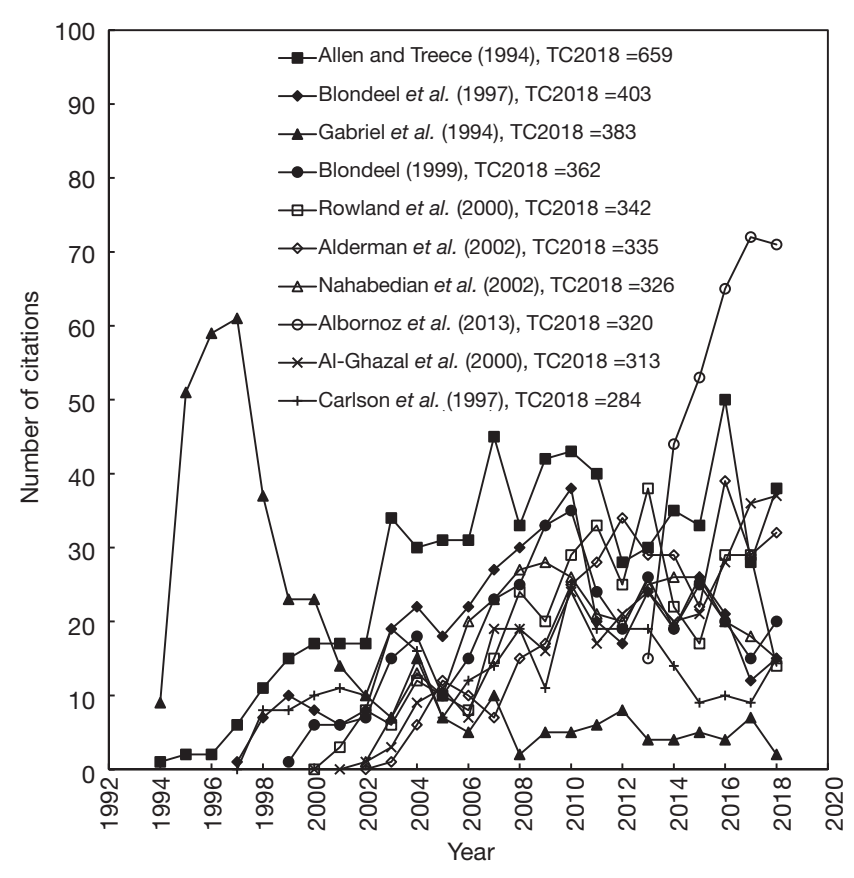

Figure 5 The citation life of the 10 most frequently cited articles with $\mathrm{TC}_{2018} \geq 284$.

because the DIEP flap-based breast reconstruction requires sophisticated microsurgical technique and the operation took hours to complete. The plateau also corresponded with the trend shift towards implant-based reconstruction after 2002 (41).

Another highly cited article entitled "Risk of connectivetissue diseases and other disorders after breast implantation" also had citations sharply increase at a rapid pace for 3 full years followed by a rapid decrease to reach a $\mathrm{C}_{2018}$ of 2 (42). The risk of connective-tissue disease (CTD) associated with breast implant was once a major concern and even led to a Food and Drug Administration (FDA) ban on the use of silicone breast implants in 1992 (43). The subsequent extensive study of the correlation of silicone implant with CTD confirmed that breast implants were not associated with an increased risk of CTD. Similarly, highly cited articles by Blondeel et al. (44), Rowland et al. (45), Nahabedian et al. (46), and Carlson et al. (47) became less popular in 2018, and their $C_{2018}$ values were $15,14,15$, and 15 respectively. Meanwhile, articles by Albornoz et al. (2) had the most impact on breast reconstruction in 2018.

Only the 4 following articles ranked in both the top ten of $\mathrm{TC}_{2018}$ and $\mathrm{C}_{2018}$.

\section{"Deep inferior epigastric perforator (DIEP) flap for} breast reconstruction" (40) (Allen and Treece, 1994) ( $\mathrm{TC} 2_{018}=659$, ranked first; $\mathrm{C} 2_{018}=38$, ranked fourth) In this article, Allen et al. introduced the DIEP flap, an innovative muscle-sparing flap pedicled on perforators from the deep epigastric artery and veins for delayed breast reconstruction. In the study, they identified the musculocutaneous perforators used for DIEP flap reconstruction. During operation, the anterior rectus sheath is opened and a desired length of perforator pedicle is exposed. The skin island elevated from the muscle fascia is transferred to the chest and the pedicle is anastomosed to the thoracodorsal vessels. The reconstructive result using the DIEP flap is comparable to the result using the transverse rectus abdominis muscle (TRAM) flap; however the muscle is preserved which allows for reduced donor site morbidity. Since its publication, the DIEP flap has become the most commonly performed free perforator flap for breast reconstruction in recent decades (48). As a pioneer in plastic surgery, Allen later developed the first superior gluteal artery perforator (SGAP) flap and the first inferior gluteal artery perforator (IGAP) flap for breast reconstruction $(40,49)$.

\section{"Complications in postmastectomy breast reconstruction: Two-year results of the Michigan breast reconstruction outcome study" (50) (Alderman et al., 2002) ( $\mathrm{TC} 2_{018}=403$, ranked sixth; $\mathrm{C} 2_{018}=38$, ranked eighth)}

This prospective multicenter cohort study enrolled 326 patients from 12 centers. The 2 -year-followup study extracted complication data from all patients undergoing breast reconstruction, including immediate and delayed breast reconstruction. The authors concluded that compared with delayed breast reconstruction, immediate breast reconstruction had a significantly higher complication rate, while the reconstruction type did not impact the complication rates. They also found that there were trends for higher complication rates in patients who received radiotherapy and chemotherapy; however, only higher BMI was a significant risk factor for complications. It was one of the first few studies that offered a comprehensive operational outcome with long-term followup. Their conclusion that immediate breast reconstruction would result in more complications than delayed breast reconstruction was confirmed in subsequent studies $(51,52)$. 
"A paradigm shift in U.S. breast reconstruction: Increasing implant rates" (2) (Albornoz et al., 2013) $\left(T C 2_{018}=320\right.$, ranked eight; $C 2_{018}=71$, ranked first $)$

Based on a national database, the study was able to support the widely accepted trend in breast reconstruction: an increase in immediate reconstruction rate corresponds to an increase in implant-based reconstruction rate. The implantbased breast reconstruction rate increased $203 \%$, while the autologous breast reconstruction rate remained unchanged. The authors' investigation revealed the shift was related to multiple factors, including patients' preference to a shorter recovery time, less donor-site morbidity related to implantbased breast reconstruction, a limited number of qualified surgeons to perform microsurgery required for autologous breast reconstruction, and the reduced burden of implantbased breast reconstruction on the operational time and insurance coverage. This trend endured until a more recent study (53).

The indication for an implant based breast reconstruction, both immediate and delayed, is primarily when the patient wants such a reconstruction given that they have been adequately informed on the different options. Implant-based reconstruction can preferably be performed in nonradiated, nonsmoking women with without hypertension and a BMI between 23 and 30 , who have nonptotic or limited ptotic breasts with a wellvascularized, thick tissue layer following mastectomy. The implant-based reconstructions can be performed as a 2-staged expander to implant procedure or as a direct-to-implant breast reconstruction (54-56). Since the introduction of acellular dermal matrix (ADM) for immediate breast reconstruction by Salzberg in 2001, there has been an increase in the use of mesh, both biological and synthetic, for breast reconstruction. The use of an ADM or synthetic mesh allows for reconstruction of a more naturalappearing breast (57-60). The use of ADM and mesh for breast reconstruction is gaining ground worldwide. However, the use of mesh and the selection of mesh type is not yet standardized, and seems to be related to surgeon preferences. We do not presently know which matrix or mesh is the best for breast reconstruction, and studies that compare the outcomes following the use of different meshes are needed. However, new types of meshes are introduced at a rapid pace, which makes the selection of mesh and comparison of outcomes difficult.

Implant-based reconstruction can also be used in large and ptotic breasts when performing the reconstruction as a staged procedure, starting with preshaping the breast by mastopexy or a breast reduction 3 months prior to mastectomy and immediate breast reconstruction (56). The reconstruction can be performed using subpectoral or a prepectoral implant placement depending on the patient wishes in relation to breast animation deformity and the quality of the mastectomy flaps. However, literature related to the classification and significance of breast animation deformity according to patients' and surgeons' perspectives is still very limited. The contraindication for prepectoral implant placement is thin mastectomy flaps and often low BMI $(61,62)$.

"Comparison of the psychological aspects and patient satisfaction following breast conserving surgery, simple mastectomy and breast reconstruction" (63) (Al-Ghazal et al., 2000) ( $\mathrm{TC} 2_{018}=313$, ranked $9 \mathrm{t}^{\mathrm{hi}} \mathrm{C} 2_{018}=37$, ranked fifth)

The retrospective study evaluated the psychosocial morbidity and satisfaction of patients with breast cancer undergoing breast-conserving surgery, simple mastectomy, and breast reconstruction. The mastectomy group had the highest morbidity, and the worst psychosocial condition and patient satisfaction related to aesthetics. The breast-conserving surgery group had the highest patient satisfaction related to cosmetic outcome and psychosocial aspects. The results demonstrated that although breast reconstruction could not compare with breast-conserving surgery in terms of patients' quality of life, there was a strong indication for breast reconstruction after mastectomy. There is an increasing focus on patientrelated outcomes and what appears to be a particular focus on the use of Breast-Q for evaluation of patients; quality of life following breast reconstruction. However, the use of Breast-Q is still rather new, and surgeons are still learning how to use and interperet this and other patient-reported outcome measures (PROMs) for use in daily clinical work. Furthermore, evaluation of the data obtained over time from the different PROMs and a confirmation that they represent the actual outcomes as perceived by the patients is still required (64).

\section{Research trends and tendencies}

The distribution of words in article titles, abstracts, author keywords and KeyWords Plus, as a comprehensive analysis, is informative to reveal the research highlights and their development tracks within research domains.

According to this, the possible major research highlights 


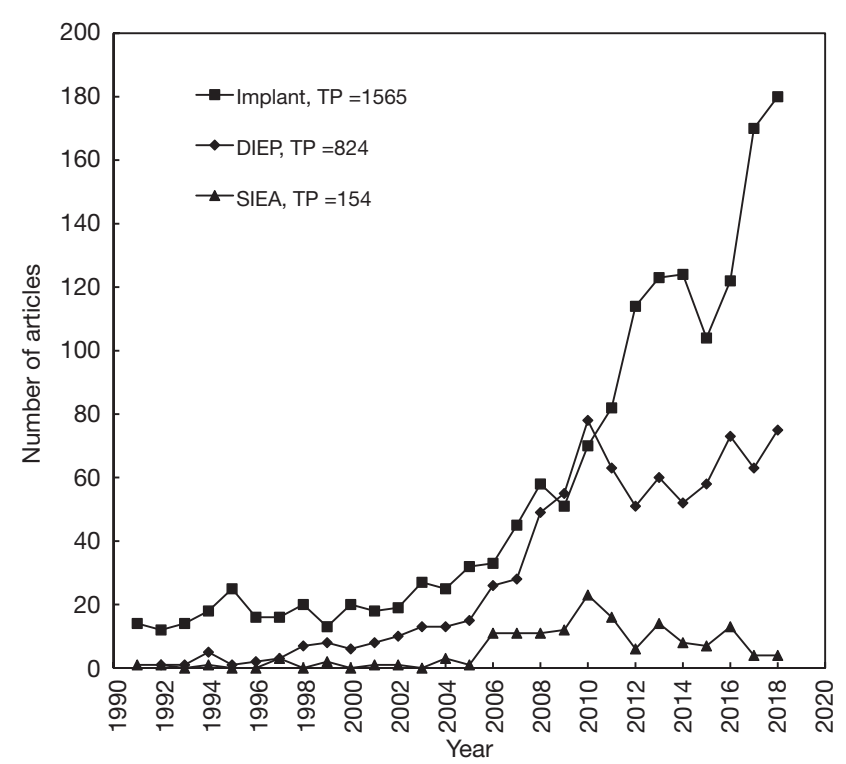

Figure 6 Developments of implant, DIEP, and SIEA. DIEP, deep inferior epigastric perforator; SIEA, superficial inferior epigastric artery.

in breast reconstruction are described below.

(I) Implant, including supporting words such as: implant, implants, implant-based, breast implant, breast implants, expander implant, direct to implant, implant related, implant reconstruction, and silicone implants.

(II) DIEP, including supporting words such as: DIEP, DIEP flap, DIEP flaps, DIEPs, free DIEP, DIEP flap, deep inferior epigastric artery perforator flap, deep inferior epigastric artery, DIEP, and deep inferior epigastric artery perforator.

(III) Superficial inferior epigastric artery (SIEA), including supporting words such as SIEA, SIEA flaps, SIEA flap, SIEA-based, SIEAs, superficial inferior epigastric vein, SIEA flap, and SIEA.

Figure 6 compares the distributions of these three main reconstructive focuses in breast reconstruction research.

However other options have been used for reconstruction, including TRAM flap, back-based flaps, gluteal flaps, and many other flaps, with the most common still being DIEP flap and SIEA flap. The latissimus dorsi (LD) flap was the earliest musculocutaneous flap to reconstruct breast defects (65). However, the LD flap often provides insufficient volume for total breast reconstruction and it is often combined with an implant to reconstruct the breast. The pedicled TRAM flap was introduced by
Hartrampf et al. in 1982 with an ample amount of soft tissue to reconstruct the breast (66). The free TRAM flap was later developed and pedicled on the DIEPs. In 1994, Allen was able to harvest a flap pedicled on the DIEPs from the abdomen while keeping the abdominal muscles intact (40). Subsequently, the SIEA-based flap was developed for breast reconstruction in 1999 (67). Both the DIEP and SIEA flaps provided an adequate amount of soft tissue and favorable donor sites and became the most popular flaps for autologous breast reconstruction both in practice and in research. Despite these advantages, the time-consuming operative process and high requirements for microsurgeons limit their wider application to some extent.

The indication for autologous breast reconstruction is often sequelae following radiation therapy and/or patients wishes (40). Over time, the most popular solutions have been, and still are, the DIEP flap and the musculus latissimus dorsi flap, with the latter often being used in combination with an implant. However, there are many different types of pedicled flaps from the back, ranging from the extended LD flap to the pedicled TAP flap in combination with an implant (68). Some patients do not wish to have a "foreign body" in terms of an implant, and thus subsequent re-operations in relation to capsula contracture or change of implant size are performed, and the autologous DIEP flap is chosen as a more permanent solution.

The application of silicone implants in breast reconstruction dates back to 1963 , when the prosthesis was implanted in a delayed fashion following mastectomy (69). Its relatively simple operative steps and short time for recovery provide a relative benefit to both surgeons and patients. Research-related to implant-based reconstruction has evolved ever since. The immediate implant-based breast reconstruction and the expander to implant allowed for better tissue compatibility $(70,71)$. Nevertheless, the safety of silicone implants was questioned, especially in relation to its possible link with auto-immune disorders (42). In 1992, the use of silicone implants was suspended by the FDA (43). As the only approved breast implant, the saline-filled implant dominated the market during that time. It was not until 2006 that the ban of silicone implants was lifted (72).

The current disputes concerning implant-based breast reconstruction include a number issues: (I) whether it is necessary to ban the use of textured implants because of their likely correlation to breast implant-associated 
anaplastic large cell lymphoma (BIA-ALCL), (II) whether it would be safe and effective to incorporate AlloDerm into the operation, and (III) whether placing the implant in the pre-pectoral plane would achieve better results (73-75). Based on our knowledge about BIA-ALCL, we should not abandon the use of implant-based breast reconstructions, but we should certainly be aware of the risk and the symptoms and treat patients at risk accordingly. One can foresee that with the current focus on BIA-ALCL, there will be an increase in patients wanting an autologous breast reconstruction without an implant.

\section{Questions to be further considered}

What is the indication for fat graft breast reconstruction, implant-based breast reconstruction and autologous breast reconstruction in your practice? Which one has the best outcome in terms of complication and cosmetics?

\section{Expert opinion: Dr. Jørn Bo Thomsen}

(I) Fat graft breast reconstruction: Indications include women with a substantial BMI, where other reconstructive possibilities are not possible. Otherwise fat grafting is used as a supplement and contouring before and after other types of breast reconstruction.

(II) Implant-based breast reconstruction: Indications include most women scheduled for immediate breast reconstruction, when the skin is non-radiated, the mastectomy flaps thick and well-perfused, preferably tested by ICG.

(III) Autologous breast reconstruction: Indications include immediate (when logistically possible) or delayed breast reconstruction, where the patient wants an autologous reconstruction. If the patient has had radiation therapy, then we always opt for autologous reconstruction. There of course has to be a sufficient amount of tissue at the donor site.

Complication outcomes: in the short and long-term outcomes, autologous reconstructions and fatgrafting have the lowest complication rates, and implant-based reconstructions have the highest. Cosmetic outcomes: autologous reconstructions have the best long-term results, implant-based reconstructions have the best short-term results, and fat graftbased reconstructions have the worst cosmetic results.

\section{Expert opinion: Dr. Maurice Y. Nahabedian}

(I) Of these options, I typically recommend autologous and prosthetic breast reconstruction. I do not recommend fat grafting as a sole modality because it would take too long and require too many procedures. I will frequently use fat grafting to correct contour abnormalities.

(II) My indications for implant-based reconstruction include patient preference, thin body habitus, cases where the patient is not a candidate for autologous reconstruction due to prior abdominal operations or lack of suitable donor sites. Typically, implant patients are younger and more physically active and do not want the downtime associated with autologous reconstruction. I recommend 2-stage reconstruction in $70 \%$ of women and direct-to-implant (DTI) in $30 \%$ of patients. DTI is recommended in women with small-to-medium size breasts typically with a bra cup size that ranges from A to C. In patients with small breast that have nipple-sparing mastectomy, my preference is DTI. In patients that with a removed nipple areolar complex, I typically recommend 2-stage reconstruction.

(III) My indications for autologous reconstruction include patient preference, a history of prior radiation therapy, and patients with sufficient donor site tissue.

\section{Expert opinion: Dr. Naohiro Ishii}

Fat graft breast reconstruction is often used for augmentation after partial mastectomy, implant-based breast reconstruction, and autologous breast reconstruction. Total breast reconstruction using only a fat graft may be applied for patients with breasts smaller than B cup size. Absorption and necrosis after fat grafting remain a challenging problem. Implant-based breast reconstruction is less invasive; therefore, it may be the most popular method for breast reconstruction. However, it cannot be applied to patients with breast ptosis or large breasts without revision surgery for the contralateral breast. Furthermore, collapse may occur in the long-term. Autologous breast reconstruction may be more invasive than implant-based reconstruction and can cause flap necrosis; nevertheless, contour and safety for the long-term period are better than those of other methods. Furthermore, autologous breast reconstruction can be safely applied to patients after radiotherapy. Considering these matters, I think autologous breast reconstruction has the best outcome in terms of complications and cosmetics.

\section{Expert opinion: Dr. Warren M. Rozen}

I use fat grafting for secondary, revisionary surgery in breast 
reconstruction, but not for primary breast reconstruction. I therefore offer patients both alloplastic and autologous options.

The preference for one or the other significantly depends on several factors: immediate or delayed reconstruction; volume of desired reconstruction aimed; amount of breast ptosis; prior or future radiotherapy; or the need for other adjuvant therapy.

My preference is autologous reconstruction in general, due to the aesthetic outcome and need for fewer secondary procedures (such as serial expansion and implant exchange).

In the case of radiotherapy, I prefer to perform a delayed reconstruction after radiotherapy, whether the mastectomy is performed before or prior to the radiotherapy being given.

\section{How can the use of acellular dermal matrix (ADM) be standardized?}

\section{Expert opinion: Dr. Jørn Bo Thomsen}

We use synthetical mesh, ADM, or acellular mesodermal matrix for all our immediate implant-based breast reconstructions; most of these are straight to implant breast reconstructions. It is difficult to standardize the use of mesh as there are so many different products; however, the preand subpectoral techniques are fairly standard as we have described in recent publications.

\section{Expert opinion: Dr. Maurice Y. Nahabedian}

The use of ADM is very common in my practice and is limited to those patients who have prosthetic reconstruction. The ADM is used for several reasons including adding tissue support to the mastectomy, reducing fibrous scar formation around the implant, compartmentalizing the implant in the mastectomy space, and minimizing the risk of implant migration or malposition. Its use is very important in DTI reconstruction because without it, compartmentalization of the device would not be possible.

\section{Expert opinion: Dr. Naohiro Ishii}

The acellular dermal matrix is useful for reinforcing the thin skin envelopes. It should be used if available when the tissue expander cannot be completely covered with the pectoralis major muscle and serratus anterior fascia or muscle in the tissue expander insertion. However, the use of acellular dermal matrix is still not applicable for insurance in many countries, including Japan.

\section{Expert opinion: Dr. Warren M. Rozen}

Acellular dermal matrix is used to augment implant coverage for subcutaneous or partial-subcutaneous implants. This allows for increased fixed-volume implant and potentially facilitates single-stage reconstructions. The benefits of using ADM thus include decreasing or eliminating the need for tissue expanders, improved aesthetic outcome, fewer expansions, and decreased incidence of capsular contracture.

The indications are an alternative to 2 -stage reconstruction of breast using an expander or implant-based reconstruction, revision breast surgery, or post-radiotherapy surgery.

\section{Do you preform prepectoral implant-based breast reconstruction? What is the indication and contraindication?}

\section{Expert opinion: Dr. Jørn Bo Thomsen}

Yes, the indication is when the mastectomy flaps are thick and well-vascularised and when the patient wishes to avoid breast animation deformity. Women with very large breasts are not candidates for the prepectoral technique as there is a risk of bottoming out despite the use of mesh.

\section{Expert opinion: Dr. Maurice Y. Nahabedian}

I regularly perform prepectoral breast reconstruction. The indications for prepectoral reconstruction the need to eliminate the risk of animation deformity, to optimally position the implant or expander on the chest wall to mimic that of the natural breast, or to reduce the incidence of muscle spasm and pain. Requirements for prepectoral breast reconstruction include adequate thickness and perfusion of the mastectomy skin flap. If the skin is poorly perfused or too thin, prepectoral reconstruction is not advised. Other contraindications for pre-pectoral reconstruction include active tobacco use, poorly controlled diabetes mellitus, and tumors that are within $5 \mathrm{~mm}$ of the pectoralis major muscle.

\section{Expert opinion: Dr. Naohiro Ishii}

I insert implants in the upper pole and include a suture line under the pectoralis major muscle and in the lower pole under the subcutaneous tissue. I think the indications for prepectoral implant-based breast reconstruction are patients with small implants and thick skin envelopes; on the other hand, the contraindications are patients with large implants and thin skin envelopes or those undergoing radiotherapy. 


\section{Expert opinion: Dr. Warren M. Rozen}

I do not perform prepectoral implant-based reconstruction. I do perform a partial submuscular, direct-to-implant reconstruction, using either dermal de-epithelialised flaps, biologics such as acellular dermal matrices, or synthetic meshes.

There are certainly benefits to this approach, such as the prevention of breast animation and reducing dysfunctional pain, reduction of mechanical forces on the implant generated by pectoral muscle contraction causing a doublebubble effect, or the potential risk of implant rupture.

However, the potential for implant migration, implant extrusion, and capsular contracture is high.

Clearly the thickness of the mastectomy flaps is a critical aspect, and a balancing of adequate coverage with oncologic clearance is an important factor in considering its use.

\section{What is the significance of BREAST-Q in postoperative evaluation?}

\section{Expert opinion: Dr. Jørn Bo Thomsen}

We use Breast-Q for all our reconstructive cases to evaluate patient satisfaction. We hope to use the result to guide future procedure selection for the individual patient. However, the long-term use and results of Breast-Q studies are needed to confirm the actual potential of Breast-Q.

\section{Expert opinion: Dr. Maurice Y. Nahabedian}

When assessing postoperative patient satisfaction, it is very important to have a scale that is validated. Validated scales such as the Breast-Q and SF-36 have been rigorously tested and analyzed for consistency and accuracy. The breast $\mathrm{Q}$ is important because it is specifically designed for the breast and is at present the best tool that we have for assessing postoperative patient satisfaction. That said, it is not perfect.

\section{Expert opinion: Dr. Naohiro Ishii}

BREAST-Q is a patient-based evaluation. Therefore, it is useful for achieving objective results. Additionally, it is useful for showing how the reconstructed breast achieves satisfaction and improves the psychosocial and sexual views of health.

\section{Expert opinion: Dr. Warren M. Rozen}

I do a range of patient-reported outcome measures, and BREAST-Q is one I do routinely use largely for its reproducibility in clinical research.
Given that it is standardized and easy to use, it has become common in research use.

\section{Do you perform antibiotic irrigation? What is your protocol?}

\section{Expert opinion: Dr. Jørn Bo Thomsen}

We just started irrigating 6 months ago, before this, we had a very good record with saline irrigation. We use 1 perioperative dose of vancomycin for irrigation of the surgical cavity.

\section{Expert opinion: Dr. Maurice Y. Nahabedian}

Yes, I perform antibiotic irrigation. My preferred solution is a $50 \%$ betadine solution (diluted with saline). I also use a triple-antibiotic solution (ancef, gentamycin, bacitracin). I irrigate the mastectomy pocket following the mastectomy with the triple-antibiotic solution, and then irrigate the final phase of the reconstruction when the implant and the ADM is in place with the betadine solution.

\section{Expert opinion: Dr. Naohiro Ishii}

Since antibiotic irrigation was proven not to decrease the risk of surgical infection, I routinely perform saline irrigation. Additionally, vacuum-assisted irrigation by saline perfusion can suppress infection of the tissue expander or implant.

\section{Expert opinion: Dr. Warren M. Rozen}

I irrigate the pocket with saline and betadine thoroughly initially, and I use a combination of antibiotic and betadine mixture for implant irrigation, as per an 'Adams' protocol: (1 g cefazolin and $80 \mathrm{mg}$ gentamicin) solution and povidone-iodine $(50 \mathrm{~mL})$ in $500 \mathrm{~mL}$ of sterile saline, with bacitracin often added for pseudomonas coverage.

\section{What is your opinion about the risk of BIA-ALCL?}

\section{Expert opinion: Dr. Jørn Bo Thomsen}

We are very aware of BIA-ALCL, and we are currently changing towards using smooth-surface implants only, which also means round implants. We test for BIA-ALCL whenever there is an indication for this.

\section{Expert opinion: Dr. Maurice Y. Nahabedian}

The risk of ALCL is very low and is associated with the use of textured surface breast implants. It has not been linked to smooth-surface devices unless there was a prior history of a 
textured device. ALCL can occur following augmentation and reconstruction, as well as with saline or silicone gel implants. I no longer place textured surface devices in patients for reconstruction or augmentation. The realistic risk of BIA-ALCL is probably between 1:2,000 and 1:3,000. There are individual surgeons who have a higher personal incidence, but this does not reflect the global incidence.

\section{Expert opinion: Dr. Naohiro Ishii}

Although the incidence rate is very low, patients with the risk of BIA-ALCL should be informed of BIA-ALCL in detail and the need for long-term follow-up including MRI. Positive and preventive removal of the implant should not be performed. A micro-textured implant applicable to insurance should be available as soon as possible.

\section{Expert opinion: Dr. Warren M. Rozen}

I am certainly aware of the risk of BIA-ALCL and modify my practise in line with the evolving risk reporting and with patient request/concern.

My management of BIA-ALCL is consistent with the evolving advice of my regional government advice (the Australian Therapeutic Goods Administration) and my society of plastic surgery (the American Society of Plastic Surgeons). I always discuss the risk of BIA-ALCL with patients as part of obtaining informed consent. Patients who are considering breast implants are made aware of the benefits and risks of the different types of implants for their clinical circumstance. They are provided with educational material to read, and I give written details about the name and type of implant and the procedure performed, including the breast implant manufacturer's labelling, patient information leaflet, and the patient-specific implant card.

I also give information regarding common presenting symptoms including asymmetry, pain, delayed effusion or seroma, or, less commonly, a mass or lymphadenopathy. Patients are encouraged to present for immediate clinical assessment should there be any change in size, shape or symptoms related to the breast and/or implant, as surgery as a result of early diagnosis can be curative.

\section{Limitations}

Bibliometrics is a quantitative analysis of publications, enabling us to evaluate unlimited number of publications in a certain field. Bibliometric analysis highly relies on the citation number of publications. But there is hardly an absolute relationship between research quality and citation frequency (76). In addition, compared with technology innovation, the publication of it is lagging behind, and as a result, the highly-cited and attention-received articles in bibliometric analysis sometimes are no longer up-to-date technology in real clinical practices. Bibliometric analysis can never replace or outstrip peer review and systematic review in terms of the hotspot analysis and guideline establishment.

\section{Conclusions}

We performed a bibliometric analysis to certain the major trends in the global research of breast reconstruction from 1991 to 2018. The study resulted in article information including citation number, publication output, categories, journals, institutions, countries, and research trends and tendencies. We hope this review can help guide future breast reconstruction research.

\section{Acknowledgments}

The authors appreciate the academic support from the AME Breast Surgery Collaborative Group.

Funding: None.

\section{Footnote}

Data Sharing Statement: Available at http://dx.doi. org/10.21037/atm-20-3476

Conflicts of Interest: All authors have completed the ICMJE uniform disclosure form (available at http://dx.doi. org/10.21037/atm-20-3476). The authors have no conflicts of interest to declare.

Ethical Statement: The authors are accountable for all aspects of the work in ensuring that questions related to the accuracy or integrity of any part of the work are appropriately investigated and resolved.

Open Access Statement: This is an Open Access article distributed in accordance with the Creative Commons Attribution-NonCommercial-NoDerivs 4.0 International License (CC BY-NC-ND 4.0), which permits the noncommercial replication and distribution of the article with the strict proviso that no changes or edits are made and the original work is properly cited (including links to both the formal publication through the relevant DOI and the license). 
See: https://creativecommons.org/licenses/by-nc-nd/4.0/.

\section{References}

1. Bray F, Ferlay J, Soerjomataram I, et al. Global cancer statistics 2018: GLOBOCAN estimates of incidence and mortality worldwide for 36 cancers in 185 countries. CA Cancer J Clin 2018;68:394-424.

2. Albornoz CR, Bach PB, Mehrara BJ, et al. A paradigm shift in U.S. Breast reconstruction: increasing implant rates. Plast Reconstr Surg 2013;131:15-23.

3. Czerny V. Plastic replacement of the breast with a lipoma. Chir Kongr Verhandl Dtsch Ges Chir 1895;7.

4. Colwell AS, Taylor EM. Recent Advances in ImplantBased Breast Reconstruction. Plast Reconstr Surg 2020;145:421e-32e.

5. Li Y, Xu G, Long X, et al. A bibliometric analysis of classic publications in web of science category of orthopedics. J Orthop Surg Res 2019;14:227.

6. Lin HW, Yu TC, Ho YS. A systemic review of human papillomavirus studies: global publication comparison and research trend analyses from 1993 to 2008. Eur J Gynaecol Oncol 2011;32:133-40.

7. Mao N, Wang MH, Ho YS. A Bibliometric Study of the Trend in Articles Related to Risk Assessment Published in Science Citation Index. Human and Ecological Risk Assessment 2010;16:801-24.

8. Fu HZ, Wang MH, Ho YS. Mapping of drinking water research: A bibliometric analysis of research output during 1992-2011. Sci Total Environ 2013;443:757-65.

9. Zhang G, Xie S, Ho YS. A bibliometric analysis of world volatile organic compounds research trends. Scientometrics 2010;83:477-92.

10. Garfield E. Keywords plus-ISIS breakthrough retrieval method. 1. Expanding your searching power on currentcontents on diskette. Current Contents 1990;32:5-9.

11. Fu HZ, Ho YS. Top cited articles in thermodynamic research. Journal of Engineering Thermophysics 2015;24:68-85.

12. Fu HZ, Wang MH, Ho YS. The most frequently cited adsorption research articles in the Science Citation Index (Expanded). J Colloid Interface Sci 2012;379:148-56.

13. Ho YS, Fu HZ. Mapping of metal-organic frameworks publications: A bibliometric analysis. Inorganic Chemistry Communications 2016;73:174-82.

14. Ho YS. Top-cited Articles in Chemical Engineering in Science Citation Index Expanded: A Bibliometric Analysis. Chinese Journal of Chemical Engineering 2012;20:478-88.
15. Ho YS. Classic articles on social work field in Social Science Citation Index: a bibliometric analysis.

Scientometrics 2014;98:137-55.

16. Chiu WT, Ho YS. Bibliometric analysis of homeopathy research during the period of 1991 to 2003. Scientometrics 2005;63:3-23.

17. Chuang KY, Wang MH, Ho YS. High-impact papers presented in the subject category of water resources in the essential science indicators database of the institute for scientific information. Scientometrics 2011;87:551-62.

18. Ho YS, Kahn M. A bibliometric study of highly cited reviews in the Science Citation Index expanded ${ }^{\mathrm{TM}}$. Journal of the Association for Information Science and Technology 2014;65:372-85.

19. Hsieh WH, Chiu WT, Lee YS, et al. Bibliometric analysis of Patent Ductus Arteriosus treatments. Scientometrics 2004;60:105-215.

20. Han JS, Ho YS. Global trends and performances of acupuncture research. Neurosci Biobehav Rev 2011;35:680-7.

21. Ho YS, Biaw Leng Lim L, Monge-Nájera J. Brunei Publications in the Science Citation Index Expanded (1973-2016): Bibliometrics and comparison with other tropical countries. J Revista de Biología Tropical 2018;66:1090-100.

22. Granzow JW, Levine JL, Chiu ES, et al. Breast reconstruction with perforator flaps. Plast Reconstr Surg 2007;120:1-12.

23. Retraction of "Breast reconstruction with perforator flaps". Plast Reconstr Surg 2008;121:1873.

24. Adams WP Jr, Rios JL, Smith SJ. Enhancing patient outcomes in aesthetic and reconstructive breast surgery using triple antibiotic breast irrigation: six-year prospective clinical study. Plast Reconstr Surg 2006;117:30-6.

25. Araco A, Caruso R, Araco F, et al. Capsular contractures: a systematic review. Plast Reconstr Surg 2009;124:1808-19.

26. Tamboto H, Vickery K, Deva AK. Subclinical (biofilm) infection causes capsular contracture in a porcine model following augmentation mammaplasty. Plast Reconstr Surg 2010;126:835-42.

27. Burkhardt BR, Fried M, Schnur PL, et al. Capsules, infection, and intraluminal antibiotics. Plast Reconstr Surg 1981;68:43-9.

28. Samargandi OA, Joukhadar N, Al Youha S, et al. Antibiotic Irrigation of Pocket for Implant-Based Breast Augmentation to Prevent Capsular Contracture: A Systematic Review. Plast Surg (Oakv) 2018;26:110-9. 29. Ueberreiter K, von Finckenstein JG, Cromme F, et al. 
BEAULI--a new and easy method for large-volume fat grafts. Handchir Mikrochir Plast Chir 2010;42:379-85.

30. Kauhanen S, Höckerstedt A. Full breast reconstruction with fat and how to recycle the "dog-ear". Gland surgery 2019;8:S297-300.

31. Hoppe DL, Ueberreiter K, Surlemont Y, et al. Breast reconstruction de novo by water-jet assisted autologous fat grafting--a retrospective study. Ger Med Sci 2013;11:Doc17.

32. Bostwick J. Breast reconstruction following mastectomy. CA Cancer J Clin 1995;45:289-304.

33. Mathes SJ, Bostwick J 3rd. A rectus abdominis myocutaneous flap to reconstruct abdominal wall defects. Br J Plast Surg 1977;30:282-3.

34. Bishop J. John Bostwick, Pickerell Award, 2001. Ann Plast Surg 2002;48:457-9.

35. Nahai F. John Bostwick, III, M.D., 1943-2001. 2001;108:785-6.

36. Gaeta TJ. Authorship: "Law" and Order. Academic Emergency Medicine 1999;6:297-301.

37. Mattsson P, Sundberg CJ, Laget P. Is correspondence reflected in the author position? A bibliometric study of the relation between corresponding author and byline position. Scientometrics 2011;87:99-105.

38. Fu HZ, Ho YS. Top cited articles in adsorption research using Y-index. Research Evaluation 2013;23:12-20.

39. Ho YS, Hartley J. Classic articles published by American scientists (1900-2014): A bibliometric analysis. Current Science 2016;111:1156-65.

40. Allen RJ, Treece P. Deep inferior epigastric perforator flap for breast reconstruction. Ann Plast Surg 1994;32:32-8.

41. Panchal H, Matros E. Current Trends in Postmastectomy Breast Reconstruction. Plastic and Reconstructive Surgery 2017;140:7S-13S.

42. Gabriel SE, O'Fallon WM, Kurland LT, et al. Risk of connective-tissue diseases and other disorders after breast implantation. N Engl J Med 1994;330:1697-702.

43. Podolsky D, Newman RJ. A ban on silicone. US News World Rep 1992;112:61-2.

44. Blondeel N, Vanderstraeten GG, Monstrey SJ, et al. The donor site morbidity of free DIEP flaps and free TRAM flaps for breast reconstruction. Br J Plast Surg 1997;50:322-30.

45. Rowland JH, Desmond KA, Meyerowitz BE, et al. Role of breast reconstructive surgery in physical and emotional outcomes among breast cancer survivors. J Natl Cancer Inst 2000;92:1422-9.

46. Nahabedian MY, Momen B, Galdino G, et al. Breast
Reconstruction with the free TRAM or DIEP flap: patient selection, choice of flap, and outcome. Plast Reconstr Surg 2002;110:466-75; discussion 476-7.

47. Carlson GW, Bostwick J 3rd, Styblo TM, et al. Skinsparing mastectomy. Oncologic and reconstructive considerations. Ann Surg 1997;225:570-5.

48. Healy C, Allen RJ Sr. The evolution of perforator flap breast reconstruction: twenty years after the first DIEP flap. J Reconstr Microsurg 2014;30:121-5.

49. Allen RJ, Tucker C Jr. Superior gluteal artery perforator free flap for breast reconstruction. Plast Reconstr Surg 1995;95:1207-12.

50. Alderman AK, Wilkins EG, Kim HM, et al. Complications in postmastectomy breast reconstruction: two-year results of the Michigan Breast Reconstruction Outcome Study. Plast Reconstr Surg 2002;109:2265-74.

51. Hangge PT, Jogerst K, Mohsen A, et al. Making an informed choice: Which breast reconstruction type has the lowest complication rate? Am J Surg 2019;218:1040-5.

52. Olsen MA, Nickel KB, Fox IK, et al. Comparison of Wound Complications After Immediate, Delayed, and Secondary Breast Reconstruction Procedures. JAMA Surg 2017;152:e172338.

53. Sheckter CC, Panchal HJ, Razdan SN, et al. The Influence of Physician Payments on the Method of Breast Reconstruction: A National Claims Analysis. Plast Reconstr Surg 2018;142:434e-42e.

54. Gunnarsson GL, Thomsen JB. Prepectoral Hammock and Direct-to-implant Breast Reconstruction in 10 Minutes: A Focus on Technique. Plast Reconstr Surg Glob Open 2018;6:e1931.

55. Gunnarsson GL, Heidemann LN, Bille C, et al. Nipple sparing mastectomy and the evolving direct to implant breast reconstruction. Gland Surg 2018;7:267-72.

56. Gunnarsson GL, Bille C, Reitsma LC, et al. Prophylactic Nipple-Sparing Mastectomy and Direct-to-Implant Reconstruction of the Large and Ptotic Breast: Is Preshaping of the Challenging Breast a Key to Success? Plast Reconstr Surg 2017;140:449-54.

57. Margulies IG, Salzberg CA. The use of acellular dermal matrix in breast reconstruction: evolution of techniques over 2 decades. Gland Surg 2019;8:3-10.

58. Margulies IG, Zoghbi Y, Jacobs J, et al. Direct to implant breast reconstruction: visualized technique. Gland Surg 2019;8:S247-50.

59. Salzberg CA. Nonexpansive immediate breast reconstruction using human acellular tissue matrix graft (AlloDerm). Ann Plast Surg 2006;57:1-5. 
60. Gunnarsson GL, Børsen-Koch M, Wamberg P, et al. How to perform a NAC sparing mastectomy using an ADM and an implant. Gland Surg 2014;3:252-7.

61. Dyrberg DL, Gunnarsson GL, Bille C, et al. A simple clinical assessment of breast animation deformity following direct-to-implant breast reconstruction. Arch Plast Surg 2019;46:535-43.

62. Dyrberg DL, Bille C, Gunnarsson GL, et al. Visualized pre- and subpectoral implant placement for immediate breast reconstruction. Gland Surg 2019;8:S251-4.

63. Al-Ghazal SK, Fallowfield L, Blamey RW. Comparison of psychological aspects and patient satisfaction following breast conserving surgery, simple mastectomy and breast reconstruction. Eur J Cancer 2000;36:1938-43.

64. Ghilli M, Mariniello MD, Camilleri V, et al. PROMs in post-mastectomy care: Patient self-reports (BREAST-Q) as a powerful instrument to personalize medical services. Eur J Surg Oncol 2020;46:1034-40.

65. Mühlbauer W, Olbrisch R. The latissimus dorsi myocutaneous flap for breast reconstruction. Chirurgia Plastica 1977;4:27-34.

66. Hartrampf CR, Scheflan M, Black PW. Breast reconstruction with a transverse abdominal island flap. Plast Reconstr Surg 1982;69:216-25.

67. Arnez ZM, Khan U, Pogorelec D, et al. Breast reconstruction using the free superficial inferior epigastric artery (SIEA) flap. Br J Plast Surg 1999;52:276-9.

68. Thomsen JB, Gunnarsson GL. The evolving breast

Cite this article as: Li Y, Wang X, Thomsen JB, Nahabedian MY, Ishii N, Rozen WM, Long X, Ho YS. Research trends and performances of breast reconstruction: a bibliometric analysis. Ann Transl Med 2020;8(22):1529. doi: 10.21037/atm-20-3476 reconstruction: from latissimus dorsi musculocutaneous flap to a propeller thoracodorsal fasciocutaneous flap. Gland Surg 2014;3:151-4.

69. Cronin TD, Brauer RO. Augmentation Mammaplasty. Surg Clin North Am 1971;51:441-52.

70. Snyderman RK, Guthrie RH. Reconstruction of the female breast following radical mastectomy. Plast Reconstr Surg 1971;47:565-7.

71. Radovan C. Breast reconstruction after mastectomy using the temporary expander. Plast Reconstr Surg 1982;69:195-208.

72. Tanne JH. FDA approves silicone breast implants 14 years after their withdrawal. BMJ 2006;333:1139.

73. Li Y, Xu G, Yu N, et al. Prepectoral Versus Subpectoral Implant-Based Breast Reconstruction: A Meta-analysis. Ann Plast Surg 2020;85:437-47.

74. Cordeiro PG, Ghione P, Ni A, et al. Risk of breast implant associated anaplastic large cell lymphoma (BIA-ALCL) in a cohort of 3546 women prospectively followed long term after reconstruction with textured breast implants. J Plast Reconstr Aesthet Surg 2020;73:841-6.

75. Tasoulis MK, Teoh V, Khan A, et al. Acellular dermal matrices as an adjunct to implant breast reconstruction: Analysis of outcomes and complications. Eur J Surg Oncol 2020;46:511-5.

76. Wallin JA. Bibliometric methods: pitfalls and possibilities. Basic Clin Pharmacol Toxicol 2005;97:261-75. 